$\mathrm{F}=76.40, \mathrm{p}<.01)$. The $4000-\mathrm{Hz}$ response has an amplitude $45 \%$ smaller than that observed in response to the $500-\mathrm{Hz}$ tone with similar but proportionately smaller differences observed at the other frequencies. At $45 \mathrm{~dB}$ HL, a similar decrease in amplitude as a function of frequency (linear trend: $F=61.78, p<.01)$ is observed. Although the decrease in amplitude observed at $1000 \mathrm{~Hz}(-07 \%)$ can be accounted for by the difference in the sound pressure levels of the $500-$ and $1000-\mathrm{Hz}$ tones, a progressive decrease is evidenced at the other frequencies which cannot be so interpreted.

\section{DISCUSSION}

The observation that, for essentially equal intensity conditions, the amplitude of the evoked response decreases with increases in frequency requires a speculative explanation. The results of earlier studies dealing with evoked responses suggest that the amplitude of the response is more linearly related to the subjective dimension of loudness than to the objective dimensions of frequency and intensity. Such a relationship would anticipate an effect of frequency manifest as changes in amplitude which are correlated with the auditory thresholds at those frequencies. Consequently, the loudness hypothesis would predict that, at equal intensities, the amplitude of the response would be greatest between 1000 and 2000 $\mathrm{Hz}$ and progressively smaller on either side of this frequency range. The limited frequency range as well as the high signal intensities used in this study preclude any definitive conclusion concerning an effect related to loudness. However, the progressive decrease in amplitude observed suggests that an alternative explanation is required.

One such explanation is that the amplitude of the evoked response is related to the number of neural elements activated at the cochlea. Since the $500-\mathrm{Hz}$ tone produces a disturbance over a larger area of the basilar membrane than the 1000-, 2000-, or $4000-\mathrm{Hz}$ tones, the $1000-\mathrm{Hz}$ tone produces a disturbance over a larger area than the $2000-$ or $4000-\mathrm{Hz}$ tones, etc., the concomitant number of neural elements activated by each frequency would decrease as the frequency increased-a relationship consistent with that observed between frequency and evoked response amplitude. Although the explanation is appealing from a parsimonious point of view, more detailed investigation is required for a more conclusive statement.

\section{REIERENCES}

BUTLER, R. A. Effects of changes in stimulus frequency and intensity on habituation of the human vertex potential. Journal of the Acoustical Society of America, 1968, 44, $945-950$.

DAVIS, H.. \& ZERLIN, S. Acoustic relations of the human vertex potential. Joumal of the Acoustical Society of America, 1966, 39 , $109-116$.

DAVIS, H., BOWERS, C., \& HIRSH, S. K. Relations of the human vertex potential to acoustic input: Loudness and masking. Joumal of the Acoustical Society of America, 1968,43, $431-438$.

ONISHI, S., \& DAVIS, H. Effects of duration and rise time of tone bursts on evoked $V$ potentials. Journal of the Acoustical Society of America, $1968,44,582-591$.

\title{
Retention and utilization of mediators by retardates'
}

JOHN G. BORKOWSKI, JOSEPH P. AHEARN, ${ }^{2}$ and JOHN PEARSON, University of Notre Dame, Notre Dame, Ind. 46556

The purpose of this study was to assess the ability of mildly retarded children to store and utilize mediational links in the $A-B, B-C, A-C$ paradigm. For three chaining groups the intervals between Lists $B-C$ and $A \cdot C$ were $30 \mathrm{sec}, 20 \mathrm{~min}$, or $24 \mathrm{~h}$. The interval between $D-C$ and $A-C$ in a control group $(A-B, D-C, A-C)$ was $30 \mathrm{sec}$. The major results showed that the $A-C$ learming for the control group was inferior to that for the mediation groups which were not different from one another.

A number of studies have demonstrated the ability of mentally retarded individuals to utilize mediational association during paired-associate (PA) learning in the chaining paradigm (Berkson \& Cantor, 1960; Borkowski \& Johnson, 1968). In this paradigm (i.e., Lists A-B, B-C, A-C), the occurrence of $A$ in Stage 3 has a tendency to elicit $B$ and the occurrence of $B$ in turn tends to evoke $C$, the correct response to the $A$ stimulus. Although there is evidence for the facilitating effect of mediation on A-C acquisition, there are limited data dealing with the ability of retardates to retain mediational links. Jensen \& Rohwer (1963) found that when retardates were presented sentences which related the stimulus and response terms of a PA list, relearning of the material after an interval of 1 week was not significantly different from the relearning of a control group having no prior "sentencemediation" during acquisition. However, a high degree of original learning for the two groups, toge ther with a relearning measure of retention, prevented an unequivocal interpretation of these results.

The present study attempted to assess more directly the ability of retardates to store and utilize highly available mediating links. Specifically, three groups of retarded Ss learned an A-C list $30 \mathrm{sec}, 20 \mathrm{~min}$, or $24 \mathrm{~h}$ after learning Lists A-B and B-C. A single control group learned List A-C $30 \mathrm{sec}$ after learning List $D-C$. Since the materials were common pictures and the criteria for the learning of Lists A-B and B-C were extremely high, it was hypothesized that the retention in terval would have minimal effect on the retardates' utilization of mediators during A-C learning.

\section{SUBJECTS}

The Ss were 78 institutionalized, mentally-re tarded children (mean IQ of 49.1 and mean $\mathrm{CA}$ of 16.2 years) from Fort Wayne State Hospital and Training Center. The majority of Ss showed some form of neurological damage. Seventeen per cent of the sample was female and $95 \%$ white. Seven Ss were unable to follow instructions or failed to reach criterion in five trials during the learning of List 1 or 2

In general, Ss were randomly assigned to the four conditions. However, since the population was limited in size, fewer patients were assigned to the control condition $(\mathrm{N}=16)$ than to the mediation conditions (Ns of 18, 18, and 19 for the $30-\mathrm{sec}, 20 \mathrm{~min}$, and $24 \mathrm{~h}$ groups, respec. tively). Ss were assigned to conditions so as to equate for mean ages and IQs.

\section{MATERIALS}

The materials and procedure were essentially similar to those used by Borkowski \& Johnson (1968). The specific materials used in the chaining (A-B, B-C, $A-C)$ and control (A-B, D-C, A-C) paradigms were highly associated object-pictures as the $A$ and $B$ terms and colors as the $C$ terms. The $C$ terms were highly associated with the B stimuli but not with the A stimuli. An example of one set of pairs used in the mediational list is: boy (A)-wagon (B), wagon (B)-red (C), boy (A)-red (C). The control condition had pictures as $D$ terms which were associated with C (e.g., apple-red) but not with $A$ or B. Six pairs 
were used in each of the three lists for both the chaining and control paradigms.

\section{PROCEDURE}

For the three mediation conditions, retention intervals between A-B, B-C acquisition and the presentation of $A-C$ were $30 \mathrm{sec}, 20 \mathrm{~min}$, or $24 \mathrm{~h}$. In the latter two conditions, Ss were either returned to their dormitories or waited in an adjoining playroom during the delay intervals. Furthermore, no information was provided concerning the subsequent A-C task. The control group had a 30-sec interval separating the D-C and A-C lists. The purpose of the single control group was primarily to establish the existence of the mediation phenomenon.

During the initial presentation of the A-B and B-C (or D-C) lists, the stimulus and response terms were presented simultaneously on $3 \times 2 \frac{1}{2}$-in. cards, each pair for a $2-\sec$ duration. The first test trial involved recognition of the correct response from among the six possible alternatives. Following the first study-test trial, the anticipation method ( $2: 2$-sec rate) was used to a criterion of two perfect recitations of the list. The order of presentation was randomized for each trial.

For the A-C list, the study-test method was used to a criterion of one perfect recitation. Duration of presentation on study trials was $3 \mathrm{sec}$ and $5 \mathrm{sec}$ for each test stimulus. The only knowledge of results during test trials consisted of "right-w rong" feedback after each response. Following A-C learning, a modified free-recall task (MMFR) was given to assess the strength of the $B$ and $\mathrm{C}$ responses.

\section{RESULTS}

There were no significant differences between the four groups on List 1 or 2. The

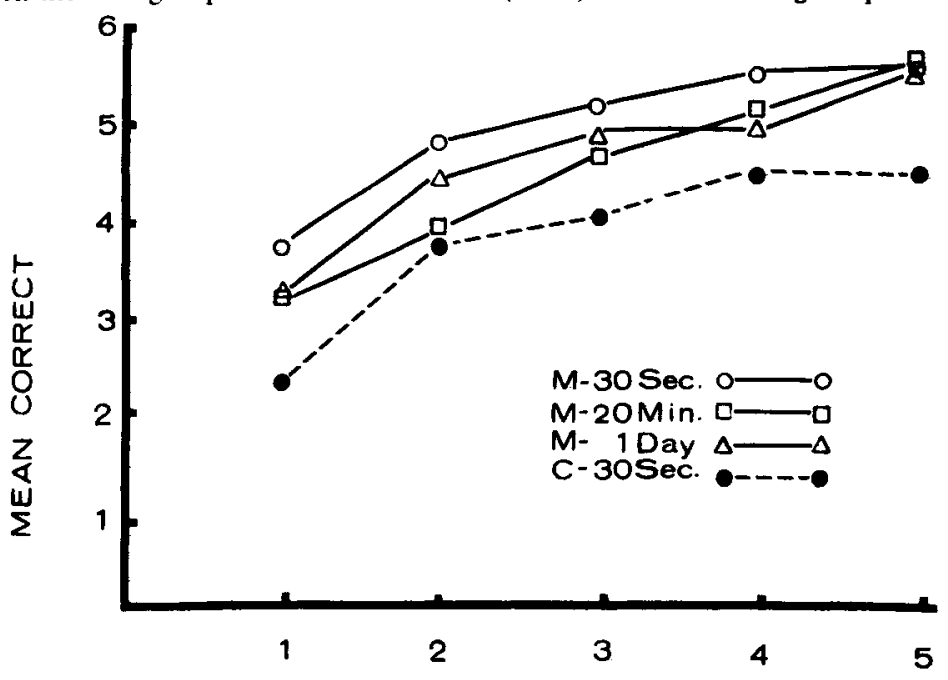

TRIALS

Fig. 1. Mean number of correct response for chaining and control paradigms as a function of the interval between Lists B-C (or D-C) and A-C. degree. Since both groups required only a few relearning trials to reach criterion, the relearning session was relatively insensitive to the assessment of the retardates' ability to store mediators.

An inspection of the present data indicates that the overall magnitude of the mediation effect was rather small, the average superiority on early trials for the mediation groups over the control being approximately one item. In addition, the MMFR task revealed little evidence which would suggest extensive use of mediational links in the three chaining groups. It should be noted that with slightly different materials and procedure (i.e., the use of a mixed-list design), Penney, Seim, \& Peters (1968) failed to find mediated facilitation even when the anticipation interval was 6 sec. Furthermore, in our laboratory we have found no evidence for mediation with retardates when verbal materials were employed. Hence it appears that while retardates can indeed retain potential mediators up to $24 \mathrm{~h}$, the phenomenon per se is severely restricted by task and procedural considerations.

One further implication of these data pertains to the prevailing "speculation" about the long-term memory capacity of retardates. That is, with highly learned materials there is some evidence which suggests that retardates retain information to the same degree as MA control Ss and show little or no memory loss with familiar materials (Belmont, 1965). Such a conclusion seems supported, in part, by the present results based on the retention and utilization of pictorial, mediational associations in the chaining paradigm.

\section{REFERENCES}

BELMONT, J. Long-term memory and mental retardation. In N. Ellis (Ed.), International review of mental retardation. Vol. 1. New Y ork: Academic Press, 1965.

BERKSON, G., \& CANTOR, G. N. A study of mediation in mentally retarded and normal school children. Journal of Educational Psy. chology, 1960, 51,82-86.

BORKOWSKI, J. G., \& JOHNSON, L. O. Mediation and the paired-associate lcarning of normals and retardates. Ainerican Journal of Mental Deficiency, 1968, 72,610-613.

JENSEN, A. R., \& ROHWER, W. D. The effect of verbal mediation on the learning and retention of paired-associates by retarded adults. American Joumal of Mental Deficiency, 1963, 68 . 80-84.

PENNEY, R, K., SEIM, R., \& PETERS, R.D. The mediational deficiency of mentally retarded children: I. The establishment of retardates' mediational deficiency. American Joumal of Mental Deficiency, 1968.72.626-630. NOTES

1. This research was supported by a grant from the Inited Cerebral Palsy of Queens, N.Y. The cooperation and assistance of the staff from l:ort Wayne State Hospital and Training Center, especially Dr. Iona Hamlett, is tratefully acknowledged.

2. Now at the University of Illinois. 